\title{
Morphometry of Spinal Nerve Composition and Thicknesses of Lumbar Plexus Nerves for Use in Clinical Applications
}

\author{
Morfometría de la Composición del Nervio Espinal y Espesores de \\ Nervios del Plexo Lumbar para su Uso en Aplicaciones Clínicas
}

\author{
Hyun-Ju Ji \& Mi-Sun Hur
}

\begin{abstract}
HYUN-JU, J. \& MI-SUN, H. Morphometry of spinal nerve composition and thicknesses of lumbar plexus nerves for use in clinical applications. Int. J. Morphol., 39(4):1006-1011, 2021.

SUMMARY: The aim of this study was to clarify the diverse spinal compositions of the branches of the lumbar plexus in terms of their prevalence rates and thicknesses. Thirty lumbar plexuses extracted from Korean adults were used in this study. The nerve fascicles were separated and traced with the aid of a surgical microscope. The thickness of each spinal nerve component was calculated based on the mean of the largest and smallest diameters using digital calipers under the surgical microscope. The most common patterns of the spinal composition of the branches of the lumbar plexus were as follows: The iliohypogastric nerve (IHN) and the ilioinguinal nerve (IIN) arose from the ventral ramus of the first lumbar nerve (L1), the genitofemoral nerve (GFN) arose from the anterior division of the ventral ramus of the second lumbar nerve (L2), and the lateral femoral cutaneous nerve (LFCN) arose from the posterior division of the ventral ramus of theL2, the femoral nerve (FN) arose from the posterior division of the ventral ramus of L2-the fourth lumbar nerve (L4), with the thickest spinal component derived from the third lumbar nerve (L3), and the obturator nerve (OBN) arose from the anterior division of the ventral ramus of L2-L4, with the thickest spinal component derived from L3. However, when L5 constituted the FN and OBN, the thickest spinal components of the FN and OBN was L4. This morphometric study has measured the thicknesses of diverse spinal components that constitute the branches of the lumbar plexus after separating the nerve fascicles. The thicknesses of the various spinal components of these branches can be compared in order to understand which make the main and minor contributions to the lower limb.
\end{abstract}

KEY WORDS: Lumbar plexus; Spinal nerve composition; Thickness.

\section{INTRODUCTION}

A lumbar plexus block is most commonly used to provide perioperative analgesia, but it can also be used as a surgical anesthetic, particularly when combined with a sciatic nerve block. The lumbar plexus block is typically used to provide analgesia following injuries or during surgeries of the hip or thigh, such as acetabular fractures, femoral neck or midshaft fractures, hip replacement, hip arthroscopy, and knee replacement, andit has also been used for chronic pain conditions such as Herpes zoster (Polania Gutierrez \& BenDavid, 2020).

The lumbar plexus lies within the psoas major muscle, and it is usually formed by the union of the ventral rami of the first lumbar nerve (L1), second lumbar nerve (L2), and third lumbar nerve (L3), and a major part of the ventral ramus of the fourth lumbar nerve (L4). In most cases it also receives some fibers from the last thoracic nerve (T12) (Hollinshead, 1982). The nerve supply of the lower limb is derived entirely from the lumbar and sacral plexuses. The three main nerves of the lumbar plexus - the lateral femoral cutaneous nerve (LFCN), femoral nerve (FN), and obturator nerve (OBN)contribute to the innervation of the lower limb. Combining blockade of these nerves with sciatic blockade can produce complete blockade of the lower limb (Sim \& Webb, 2004).

Several textbooks and articles have described the common compositions of the branches of the lumbar plexus with their considerable variations (Morris, 1947; Hollinshead, 1967, 1982; Gardner et al., 1986; Woodburne \& Burkel, 1994; Standing, 2016). The iliohypogastric nerve(IHN) usually originates from the L1ventral ramus or T12 and L1 ventral rami, the ilioinguinal nerve (IIN) usually originates from the L1 ventral ramus, the genitofemoral nerve (GFN) usually originates from L1 and L2 ventral rami, the LFCN is usually derived from L2 and L3 or L1-L3 ventral rami, the FN is usually derived from L2-L4 ventral rami, and the OBN is 
usually derived from L2-L4 or L3 and L4 ventral rami. Rouvière \& Delmas (1991) described that the GFN and LFCN usually arise from the L2 ventral ramus. However, there have been few morphometric investigations of the spinal composition of the branches of the lumbar plexus. Woo et al. (2011) reported the spinal nerve compositions and thicknesses of the branches of the lumbosacral plexus, but the thicknesses of the spinal components were not analyzed according to type of the spinal composition.

Each peripheral nerve generally contains fibers derived from multiple spinal nerves (Gardner et al., 1986).Many branches of the spinal nerves do not run separately to the muscles and skin that they innervate, instead joining or exchanging branches with other spinal nerves. This mingling and interchange-forming a plexus - gives rise to new nerves that contain fibers from multiple spinal nerves. Where the ventral branches of the spinal nerves come together to form a plexus, much of the interchange of fibers is hidden by the connective tissue that wraps all peripheral nerves. This situation often makes it very difficult to determine exactly which spinal nerves contribute to which branches of the plexus. Knowledge about this has been gained both from very careful dissections of plexuses after removing the surrounding connective tissue as well as from clinical studies (Hollinshead, 1967). Thus, tracing the nerve fascicles by identifying the origins of the spinal components is very important to obtaining accurate information about the spinal composition of the branches of the lumbar plexus.

The amount of fibers from various spinal components of the branch of the lumbar plexus can represent the degree of the segmental innervation of the skin and muscles in the lower limb. Fibers from L1 that reach the FN and OBN are apparently destined for its cutaneous branch (Hollinshead, 1982). In addition, the size and function of peripheral nerve fibers are generally proportional to their conduction velocity, with this tending to be higher in larger fibers (Sunderland, 1991; Sinnatamby, 2011). Therefore, the thickness of each spinal component that constitutes the branches can indicate the function and characteristics of the various branches of the lumbar plexus.

Due to variations in the spinal nerve composition, the dermatome distribution and the motor innervation of muscles of the lower limb can differ slightly from those expected. Thus, knowledge of these spinal variations can be helpful for predicting which branches of the lumbar plexus are affected when the spinal nerve roots are compressed or injured. If the thicknesses of spinal components of the branches of lumbar plexus are known, it is possible to identify the main and minor spinal components of each branch and the degree of the affected dermatome distribution and innervation of muscles.
Furthermore, the thickest spinal component of each branch of the lumbar plexus can differ with the type of its spinal composition.

Midlumbar nerve-root impingement or nerve-root impingement at the L2, L3, or L4 level is a cause of lumbosacral radicular syndrome found with increasing frequency in older adults (Blower, 1981; Suri et al., 2011). Moreover, the roots of L4 and the fifth lumbar nerve (L5) can be affected by sacral fractures (Häckel et al., 2020). Although the classic presentation of radicular pain in midlumbar nerveroot impingement is in the groin or anterior thigh, pain may also commonly be experienced in the calf, ankle, or foot (Rainville et al., 2003). In addition, Hirabayashi et al. (2009) described that the reason for variations in the symptoms of L3 radiculopathy is not clear. Since L2-L4 usually comprise the main branches of the lumbar plexus, knowledge of the thickness of each spinal component of the main branches can be important for distinguishing the degree of their sensory loss, muscle weakness, and neurological signs and symptoms.

Various roots and branches of the lumbar plexus course through the psoas major muscle at different levels, but they do not divide this muscle into definite planes (Hollinshead, 1971). Thus, the surgical resection of a schwannoma in the psoas major muscle (Nathanson \& Sonnino, 1987; Hida et al., 1993; Khoshyomn et al., 2002; Pazouki et al., 2011; Seo et al., 2011) can damage the branches or roots of the lumbar plexus, resulting in corresponding symptoms and signs.

Therefore, the aim of this study was to clarify the diverse spinal compositions of the branches of the lumbar plexus in terms of their prevalence rates and thicknesses. The findings of this morphometric study will be helpful for anesthesiologists and acute-pain physicians when they are diagnosing spinal root injuries and radiculopathy, performing a lumbar plexus block for perioperative analgesia and surgical anesthesia in the lower limb, and applying surgical approaches to the lumbar plexus to resect a schwannoma in the psoas major muscle.

\section{MATERIAL AND METHOD}

Thirty lumbar plexuses extracted from Korean adults (eight males and seven females; mean age 66.8 years, age range 31-82 years) were used in this study. All cadavers had been legally donated to Catholic Kwandong University College of Medicine. The present study was conducted in accordance with the Declaration of Helsinki. None of the transplant donors were from a vulnerable population and all donors or next of kin provided written informed consent that was freely given. 
This study was approved by the institutional review board of Catholic Kwandong University (IRB No. CKU-21-0903). The specimens were first immersed in $5 \%$ paraformaldehyde for 1 day and then in $0.04 \mathrm{M}$ guanidine for 1 week. The specimens were then again immersed in paraformaldehyde for 1 day, before being exposed for 1 hour to an ultrasonic cleaner in order to soften the connective tissue around the nerve bundles. The nerve fascicles were separated and traced with the aid of a surgical microscope. The thickness of each spinal nerve component was calculated based on the mean of the largest and smallest diameters using digital calipers (Mitutoyo, Kawasaki City, Japan) under the surgical microscope. The thickness of the nerve was measured at each spinal component before it formed the branches of the lumbar plexus.

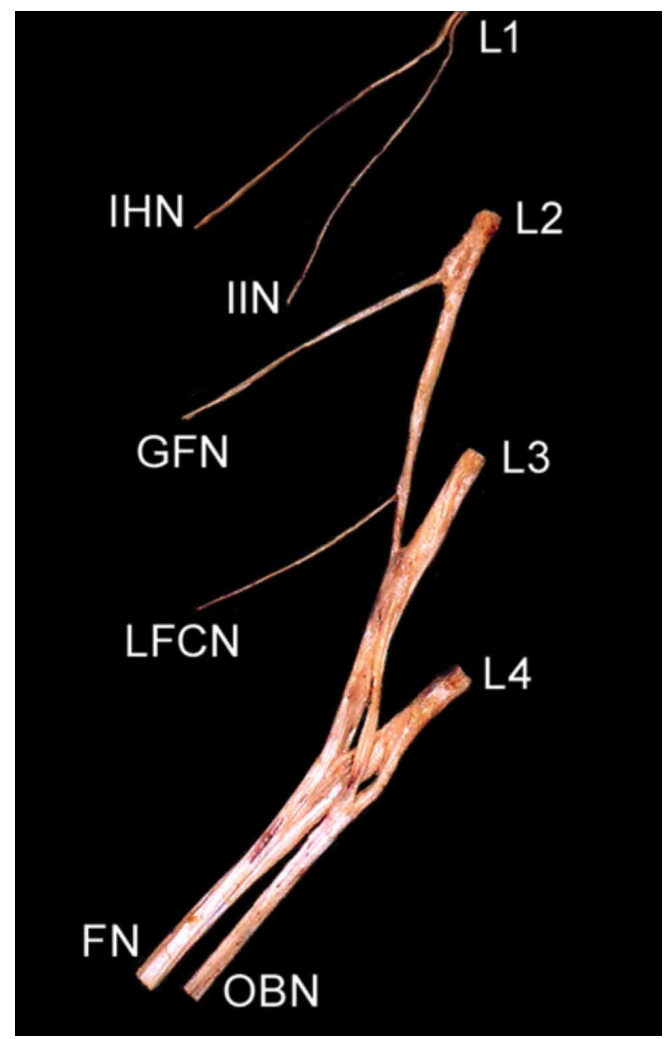

Fig. 1. Spinal composition of the branches of the lumbar plexus. The iliohypogastric nerve (IHN) and ilioinguinal nerve (IIN) arose from the ventral ramus of the first lumbar nerve (L1), the genitofemoral nerve (GFN) arose from the anterior division of the ventral ramus of the second lumbar nerve (L2), and the lateral femoral cutaneous nerve (LFCN) arose from the posterior division of the ventral ramus of L2, the femoral nerve (FN) arose from the posterior division of the ventral ramus of L2, the third lumbar nerve (L3), and the fourth lumbar nerve (L4), and the obturator nerve $(\mathrm{OBN})$ arose from the anterior division of the ventral ramus of L2-L4.

\section{RESULTS}

The lumbar plexus was formed by the union of the T12-L4, L1-L4, or L1-L5 ventral rami, and the branches of the lumbar plexus were the IHN, IIN, GFN, LFCN,FN, and OBN (Fig. 1). The IHN arose from the ventral ramus of T12in 6 of 21 specimens $(28.6$ $\%$ ) and from the ventral ramus of L1 in 15 specimens $(71.4 \%)$. The thicknesses of T12 and L1 constituting the IHN were $2.38 \pm 2.51 \mathrm{~mm}$ (mean $\pm \mathrm{SD}$ ) and $1.18 \pm 1.02 \mathrm{~mm}$, respectively. The IIN arose from the ventral ramus of L1 in 20 of 22 specimens (90.9 $\%$ ) and from the anterior division of the ventral ramus of L2 in 2 specimens $(9.1 \%)$. The thicknesses of L1 and L2 constituting the IIN were $0.61 \pm 0.69 \mathrm{~mm}$ and $0.40 \pm 0.45 \mathrm{~mm}$, respectively.

The GFN arose from the anterior division of the ventral ramus of L1-L3.The form of the GFN in the 22 investigated specimens could be classified into 5 types:

Type I ( $\mathrm{n}=2,9.1 \%)$, in which L1 constituted the GFN and was $0.56 \pm 0.59 \mathrm{~mm}$ thick.

Type II ( $\mathrm{n}=1,4.5 \%)$, in which L1 and L2 constituted the GFN and were $0.57 \pm 0.78 \mathrm{~mm}$ and $1.02 \pm 1.15 \mathrm{~mm}$ thick, respectively.

Type III $(\mathrm{n}=15,68.2 \%)$, in which L2 constituted the GFN and was $0.60 \pm 0.58 \mathrm{~mm}$ thick.

Type IV ( $\mathrm{n}=2,9.1 \%$ ), in which L2 and L3 constituted the GFN and were $0.38 \pm 0.52 \mathrm{~mm}$ and $0.28 \pm 0.22 \mathrm{~mm}$ thick, respectively.

Type V $(\mathrm{n}=2,9.1 \%)$, in which L3 constituted the GFN and was $0.98 \pm 1.15 \mathrm{~mm}$ thick.

The LFCN arose from the posterior division of the ventral ramus of $\mathrm{L} 2$ and L3, and the form of the LFCN in the 25 investigated specimens could be classified into 2 types:

Type I ( $\mathrm{n}=20,80.0 \%)$, in which L2 constituted the LFCN and was $0.73 \pm 0.75 \mathrm{~mm}$ thick.

Type II ( $\mathrm{n}=5,20.0 \%)$, in which L2 and L3 constituted the LFCN and were $0.77 \pm 0.80 \mathrm{~mm}$ and $0.73 \pm 0.77 \mathrm{~mm}$ thick, respectively.

The FN arose from the posterior division of the ventral ramus of L2-L5, and the form of the FN in the 28 investigated specimens could be classified into 3 types:

Type I ( $\mathrm{n}=23,82.1 \%)$, in which L2, L3, and L4 constituted the FN and were $1.48 \pm 1.32 \mathrm{~mm}, 2.91 \pm 1.77 \mathrm{~mm}$, and $2.19 \pm 1.45 \mathrm{~mm}$ thick, respectively (Fig. 2a).

Type II ( $\mathrm{n}=2,7.1 \%)$, in which L2, L3, L4, and L5 constituted the FN and were $0.48 \pm 0.47 \mathrm{~mm}, 2.47 \pm 1.91 \mathrm{~mm}, 2.87 \pm 1.31 \mathrm{~mm}$, and $0.51 \pm 0.50 \mathrm{~mm}$ thick, respectively. 
Type III ( $\mathrm{n}=3,10.7 \%)$, in which L3, L4, and L5 constituted the FN and were $2.11 \pm 1.76 \mathrm{~mm}, 3.30 \pm 2.41 \mathrm{~mm}$, and $1.00 \pm 0.94$ mm thick, respectively (Fig. 2b).

The OBN arose from the anterior division of the ventral ramus of $\mathrm{L} 2-\mathrm{L} 5$, and the form of the OBN in the 29 investigated specimens could be classified into 4 types:

Type I ( $\mathrm{n}=1,3.4 \%)$, in which L2 and L3 constituted the OBN and were $0.56 \pm 0.64 \mathrm{~mm}$ and $1.79 \pm 1.88 \mathrm{~mm}$ thick, respectively.

Type II ( $\mathrm{n}=12,41.4 \%)$, in which L2, L3, and L4 constituted the OBN and were $0.53 \pm 0.55 \mathrm{~mm}, 1.45 \pm 1.02 \mathrm{~mm}$, and $0.64 \pm 0.51 \mathrm{~mm}$ thick, respectively (Fig. 3).

Type III ( $\mathrm{n}=11,37.9 \%)$, in which L3 and L4 constituted the $\mathrm{OBN}$ and were $1.31 \pm 1.02 \mathrm{~mm}$ and $1.09 \pm 0.72 \mathrm{~mm}$ thick, respectively.
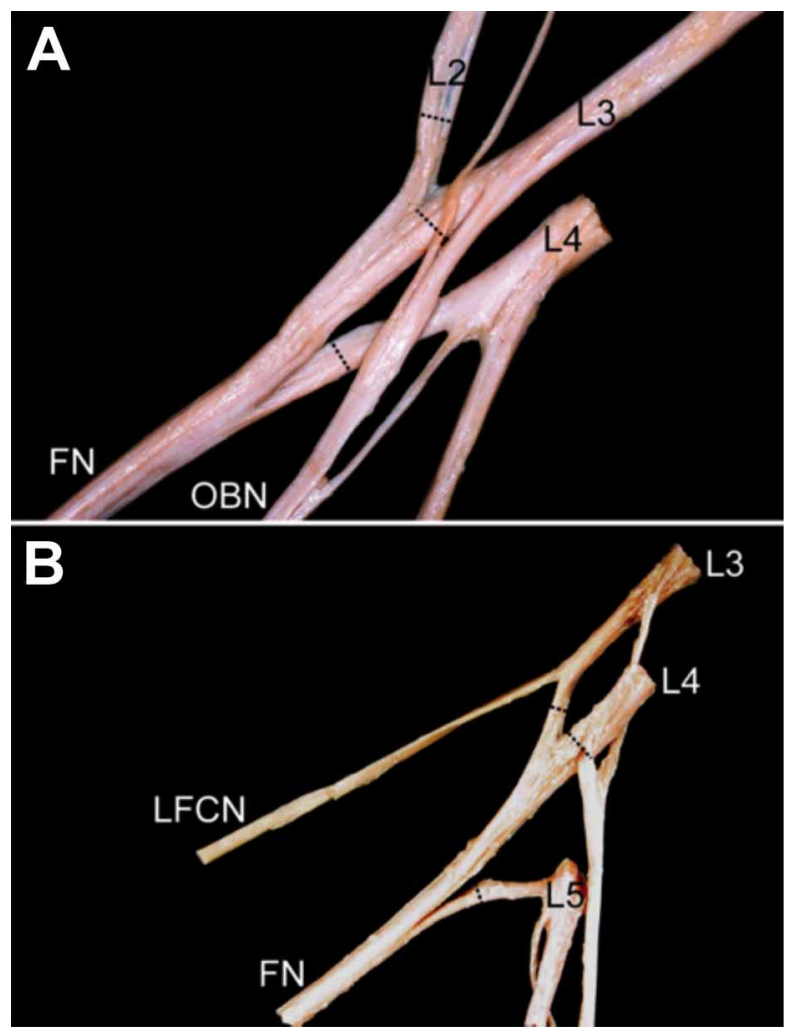

Fig. 2. Spinal composition and thicknesses of the spinal components that constituted the femoral nerve (FN). (a) When the FN arose from the second lumbar nerve (L2)-the fourth lumbar nerve (L4), the third lumbar nerve (L3) was the thickest. (b) When the FN arose from L3, L4, and the fifth lumbar nerve (L5), L4 was the thickest. Dotted lines indicate sites of measurements for the different spinal components before they formed the FN. (LFCN= lateral femoral cutaneous nerve, $\mathrm{OBN}=$ the obturator nerve).
Type IV ( $\mathrm{n}=5,17.2 \%)$, in which L3, L4, and L5 constituted the OBN and were $0.91 \pm 0.76 \mathrm{~mm}, 1.38 \pm 0.95 \mathrm{~mm}$, and $0.30 \pm 0.39 \mathrm{~mm}$ thick, respectively.

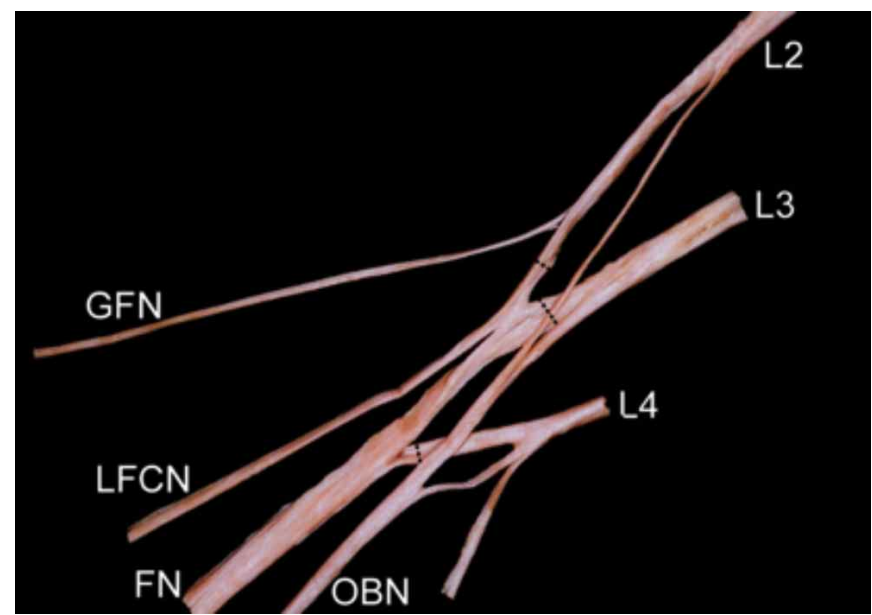

Fig. 3. Spinal composition and thicknesses of the spinal components that constituted the obturator nerve (OBN). When the OBN arose from the second lumbar nerve (L2)-the fourth lumbar nerve (L4), the third lumbar nerve (L3) was the thickest. GFN, genitofemoral nerve; LFCN, lateral femoral cutaneous nerve; FN, femoral nerve. Dotted lines indicate sites of measurements for the different spinal components before they formed the OBN.

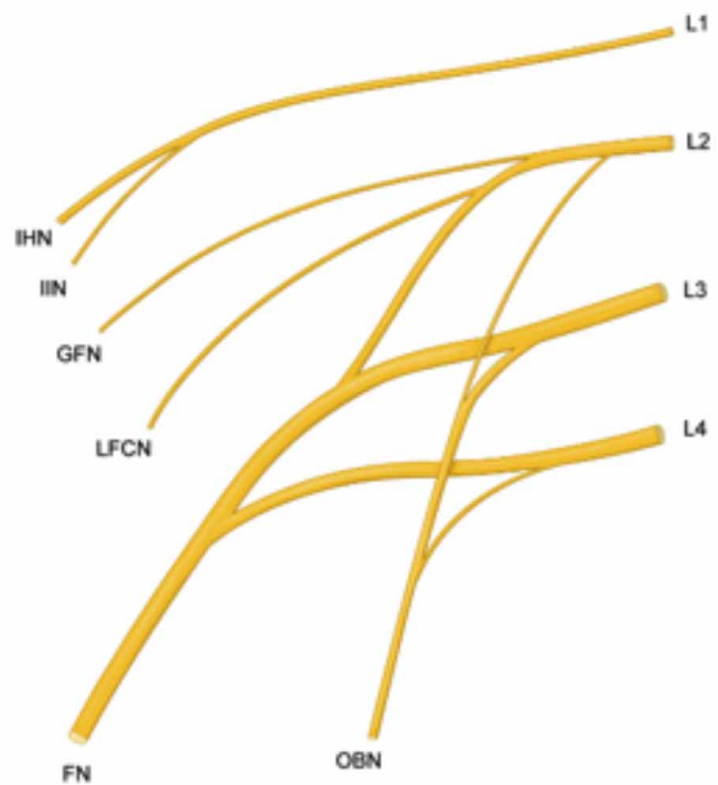

Fig. 4.T he most common pattern of the spinal composition of the branches of the lumbar plexus. The iliohypogastric nerve (IHN) and ilioinguinal nerve (IIN) arose from the first lumbar nerve (L1), the genitofemoral nerve (GFN) and the lateral femoral cutaneous nerve (LFCN) arose from the second lumbar nerve (L2), the femoral nerve (FN) arose from the second lumbar nerve (L2)-the fourth lumbar nerve (L4), with the thickest spinal component derived from the third lumbar nerve (L3), and the obturator nerve (OBN) arose from L2-L4, with the thickest spinal component derived from L3. 


\section{DISCUSSION}

This study has revealed the diversity of the spinal nerve composition along with the thicknesses of the various spinal components of the branches of the lumbar plexus by separating the nerve fascicles. The thickest spinal component of a branch differed according to its type of spinal composition. The different thicknesses of spinal components of a branch of the lumbar plexus indicated different degrees of contribution and affection to the branches, which would result in each branch have specific characteristics and functions. The most common patterns of the spinal composition of the branches of the lumbar plexus were as follows (Fig. 4): the IHN and IIN arose from L1, the GFN and LFCN arose from L2, the FN arose from L2-L4, with the thickest spinal component derived from L3, and the OBN arose from L2-L4, with the thickest spinal component derived from $\mathrm{L} 3$.

Regarding the spinal composition of the branches of the lumbar plexus, there were some discrepancies between the results of the present study and those from previous studies, which may be due to analyzing different numbers of specimens and different species. Morris described that the IHN originates from L1, after the latter has been joined by the communicating branch from $\mathrm{T} 12$, which occurs in about $50 \%$ of all cases, and it thus contains fibers of both T12 and L1. Sim \& Webb (2004) reported that the IHN mainly arose from L1 in $100 \%$ of the specimens. However, a communicating branch from T12 to L1 was not found in the present study, and the IHN mainly arose solely from L1 in $71.4 \%$ of the specimens. When the IHN arose from T12 in the present study, T12 was approximately twice as thick as L1.

Morris, Gardner et al. and Standring (2016) stated that the IIN usually originates from the L1 ventral ramus, but may also receive a contribution from T12 or L2. Sim \& Webb reported that the IIN mainly arose from L1 in $100 \%$ of the specimens. In the present study, the prevalence of the type in which the IIN arose from L1 was dominant in 90.9 $\%$ of the specimens.

The GFN mainly arose from both L1 and L2 in $91 \%$ of the specimens in the study of Sim \& Webb, whereas the GFN mainly arose from L2 in $68.2 \%$ of the specimens in the present study. Morris described that the GFN is connected to L1 and L2, but most of its fibers are derived from L2. When both L1 and L2 constituted the GFN, L2 was approximately twice as thick as L1 in the present study. In the cases in which the GFN comprised solely L1, L2, or L3, L3 was the thickest among these three nerves.
Morris described that the LFCN receives fibers from the dorsal branches of the anterior primary divisions of L2 and L3, and frequently also some fibers from L1. Sim \& Webb stated that the LFCN mainly arose from L2 and L3 in $57 \%$ of the specimens. In the present study, the LFCN mainly arose from L 2 in $80.0 \%$ of the specimens.

Sim \& Webb and the present study found that the FN mainly arose from L2-L4 in $100 \%$ and $82.1 \%$ of the specimens, respectively. Hollinshead (1982) described that the FN originates mostly from L2, L3, and L4, with most of the fibers derived from the latter two. Gardner et al. described that the FN arises principally from $\mathrm{L} 4$, and also from $\mathrm{L} 2$ and L3. In the most common type of the FN of the present study, L3 was the thickest among L2, L3, and L4. In addition, L3 was approximately twice as thick as L2, while the thickness of L4 was intermediate between those of L2 and L3. However, when L5 contributed to the FN, such as in type II (L2-L5, $7.1 \%$ ) and type III (L3-L5, $10.7 \%$ ), L4 was the thickest of the spinal components.

Gardner et al. described that the OBN usually arises from L 3 and L4, sometimes from L2, and occasionally from L5. Morris described that the OBN contains fibers from the anterior primary divisions of the L2, L3, and L4, but its largest root is derived from L3. Sim \& Webb stated that the OBN mainly arose from L2-L4 in $97 \%$ of the specimens. However, in the present study, L2-L4 constituted the OBN in $41.4 \%$ of the specimens, while the two types that arose from L3 and L4 and from L3-L5 comprised $37.9 \%$ and $17.2 \%$ of the specimens, respectively. In the type in which L2-L4 constituted the OBN in the present study, L3 was typically more than twice as thick as L2 and L4. However, when L5 constituted the OBN, such as in type IV (L3-L5, $17.2 \%)$, L4 was the thickest among L3-L5. Morris, Hollinshead (1982), and Woodburne \& Burkel stated the accessory OBN in 8.4 29\% of their specimens, arising from L3 or L3 and L4. However, the accessory OBN was not found in the present study.

L5 is reportedly the most commonly injured nerve root (Pateder \& Kostuik, 2005). Horwitz (1939) reported that the lumbar plexus receives fibers from L5 in about 12 $\%$ of plexuses. In the present study, L5 constituted the FN and $\mathrm{OBN}$ in $17.8 \%$ and $17.2 \%$ of the specimens, respectively. When $\mathrm{L} 5$ constituted the $\mathrm{FN}$ and $\mathrm{OBN}$, the thickest spinal components of the FN and OBN differed from those of their most common types. The FN is the largest branch of the lumbar plexus (Woodburne \& Burkel) and the FN and OBN contain both sensory and motor components. Thus, when L5 is damaged, the FN and OBN can be partially affected in some patients, resulting in neuropathic pain and neurological symptoms and signs. Damage to the FN and 
OBN including L5 or their blocking for regional anesthesia can especially result in diminished skin sensation and weakness of muscles innervated by L4, indicating their different contributions to innervation ofthe skin and muscles.

In conclusion, this morphometric study has measured the thicknesses of diverse spinal components that constitute the branches of the lumbar plexus after separating the nerve fascicles. The thicknesses of the various spinal components of these branches can be compared in order to understand which make the main and minor contributions to the lower limb. The obtained results can be a useful reference for diagnosing various symptoms and signs related to spinal root radiculopathy and for performing lumbar plexus block for perioperative analgesia and surgical anesthesia in the lower limb.

HYUN-JU, J. \& MI-SUN, H. Morfometría de la composición del nervio espinal y espesores de nervios del plexo lumbar para su uso en aplicaciones clínicas. Int. J. Morphol., 39(4):1006-1011, 2021.

RESUMEN: El objetivo de este estudio fue evaluar las diversas composiciones espinales de los ramos del plexo lumbar en cuanto a sus tasas de prevalencia y grosor. Se utilizaron treinta plexos lumbares extraídos de individuos adultos coreanos. Se separaron y trazaron los fascículos nerviosos por medio de un microscopio quirúrgico. El grosor de cada componente del nervio espinal se calculó con base en la media de los diámetros mayor y menor utilizando calibradores digitales bajo el microscopio. Los patrones más comunes de la composición espinal de los ramos del plexo lumbar fueron los siguientes: el nervio iliohipogástrico (NIH) y el nervio ilioinguinal (NII) surgieron del ramo ventral del primer nervio lumbar (L1). El nervio genitofemoral (NGF) surgió de la división anterior del ramo ventral del segundo nervio lumbar (L2). El nervio cutáneo femoral lateral (NCFM) surgió de la división posterior del ramo ventral L2. El nervio femoral (NF) surgió de la división posterior del ramo ventral de L2. El cuarto nervio lumbar (L4), con el componente espinal más grueso derivado del tercer nervio lumbar (L3) y el nervio obturador (NOB) surgieron de la división anterior del ramo ventral de L2-L4, con el componente espinal más grueso derivado de L3. Sin embargo, cuando L5 constituía el NF y NOB, los componentes espinales más gruesos del NF y NOB eran de L4. Este estudio morfométrico analizó los espesores de diversos componentes espinales que constituyen las ramas del plexo lumbar después de separar los fascículos nerviosos. Es posible comparar los espesores de los diversos componentes espinales de estos ramos para comprender las contribuciones principales y menores al miembro inferior.

PALABRAS CLAVE: Plexo lumbar; Composición del nervio espinal; Espesor.

\section{REFERENCES}

Blower, P. W. Neurologic patterns in unilateral sciatica. A prospective study of 100 new cases. Spine (Phila Pa 1976), 6(2):175-9, 1981.

Gardner, E.; O'Rahilly, R. \& Müller, F. Gardner-Gray-O'Rahilly. Anatomy: A Regional Study of Human Structure. $5^{\text {th }}$ ed. Philadelphia, W. B. Saunders Company, 1986
Häckel, S.; Albers, C. E.; Bastian, J. D.; Hoppe, S.; Benneker, L. M. \& Keel, M. J. B. Direct anterior decompression of L4 and L5 nerve root in sacral fractures using the pararectus approach: a technical note. Arch. Orthop. Trauma Surg., 140(3):343-51, 2020.

Hida, K.; Iwasaki, Y.; Abe, H.; Itamoto, K. \& Kaneda, K. Schwannoma in the psoas muscle removed by the retroperitoneal approach. Br. J. Neurosurg., 7(2):213$5,1993$.

Hirabayashi, H.; Takahashi, J.; Hashidate, H.; Ogihara, N.; Tashiro, A.; Misawa, H.; Ebara, S.; Mitsui, K.; Wakabayashi, S. \& Kato, H. Characteristics of L3 nerve root radiculopathy. Surg Neurol., 72(1):36-40, 2009.

Hollinshead, W. H. Anatomy for Surgeons: The Back and Limbs. Volume 3. 3rd ed. Philadelphia, Harper \& Row, 1982.

Hollinshead, W. H. Anatomy for Surgeons: The Thorax, Abdomen, and Pelvis. Volume 2. 2nd ed. New York, Harper \& Row, 1971.

Hollinshead, W. H. Textbook of Anatomy. 2nd ed. New Work, Harper \& Row, 1967.

Horwitz, M. T. The anatomy of (A) the lumbosacral nerve plexus-its relation to variations of vertebral segmentation, and (B), the posterior sacral nerve plexus. Anat. Rec., 74(1):91-107, 1939.

Khoshyomn, S.; Barth, K. N.; Christman, R. A.; Braff, S. P. \& Wilson, J. T. Torsion a lumbar nerve root schwannoma. Pediatr Neurosurg. 37(4):206-9, 2002.

Morris, H. Morris' Human Anatomy: A Complete Systematic Treatise. $10^{\text {th }}$ ed. Philadelphia, Blakiston Co., 1947.

Nathanson, S. D. \& Sonnino, R. An anatomic approach to tumors of the psoas major muscle. Surgery, 101(6):763-6, 1987.

Pateder, D. B. \& Kostuik, J. P. Lumbar nerve root palsy after adult spinal deformity surgery. Spine (Phila Pa 1976), 30(14):1632-6, 2005.

Pazouki, A.; Khalaj, A.; Shapoori, P.; Vaziri, M. \& Najafi, L. Laparoscopic resection of a retroperitoneal schwannoma. Surg. Laparosc. Endosc. Percutan. Tech., 21(6):e326-8, 2011.

Polania Gutierrez, J. J. \& Ben-David, B. Lumbar Plexus Block. Treasure Island (FL), StatPearls Publishing, 2020.

Rainville, J.; Jouve, C.; Finno, M. \& Limke, J. Comparison of four tests of quadriceps strength in L3 or L4 radiculopathies. Spine (Phila Pa 1976), 28(21):2466-71, 2003.

Rouvière, H. \& Delmas, A. Anatomie Humaine. Tome 3. Membres, Système Nerveux Central. 13th ed. Paris, Masson, 1991.

Seo, I. Y.; Boldbaatr, Y. \& Choi, K. H. Laparoscopic resection of ancient schwannoma embedded in the psoas muscle. Surg. Laparosc. Endosc. Percutan. Tech., 21(6):e336-8, 2011.

Sim, I. W. \& Webb, T. Anatomy and anaesthesia of the lumbar somatic plexus. Anaesth. Intensive Care., 32(2):178-87, 2004.

Sinnatamby, C. S. Last's Anatomy: Regional and Applied. $12^{\text {th }}$ ed. Edinburgh, Churchill Livingstone, 2011.

Standring, S. Gray's Anatomy. The Anatomical Basis of Clinical Practice. $41^{\text {st }}$ ed. New York, Elsevier/Churchill Livingstone, 2016.

Sunderland, S. Nerve Injuries and their Repair: A Critical Appraisal. New York, Churchill Livingstone, 1991.

Suri, P.; Rainville, J.; Katz, J. N.; Jouve, C.; Hartigan, C.; Limke, J.; Pena, E.; Li, L.; Swaim, B. \& Hunter, D. J. The accuracy of the physical examination for the diagnosis of midlumbar and low lumbar nerve root impingement. Spine (Phila Pa 1976), 36(1):63-73, 2011.

Woo, J. S.; Hur, M. S.; Kim, H. J. \& Lee, K. S. Spinal nerve compositions of the terminal branches of the lumbosacral plexus. Korean J. Phys. Anthropol, 24(2):97-103, 2011.

Woodburne, R. T. \& Burkel, W. E. Essentials of Human Anatomy. $9^{\text {th }}$ ed. New York, Oxford University Press, 1994.

\section{Corresponding author: \\ Mi-Sun Hur, PhD \\ Department of Anatomy \\ Catholic Kwandong University College of Medicine \\ 24, Beomil-ro 579 \\ Gangneung, 25601 -KOREA}

E-mail: mshur@cku.ac.kr

Received: 31-03-2021

Accepted: 07-05-2021 